\title{
Ecology of Larval Development of the Crustacean Euphausia superba. Change in Dominant Larval Forms as a Function of Environmental Conditions
}

\author{
R. R. Makarov and V. V. Maslennikov \\ All-Union Research Institute of Marine Fisheries and Oceanography (VNIRO), 17a, Krasnoselskaja Street, Moscow 107140, \\ USSR
}

\begin{abstract}
Variability and patterns of dominance in larval forms of Euphausia superba at the Furcilia-I stage have been investigated in the Scotia Sea. Here, two different water bodies can be distinguished: the Antarctic Circumpolar current (ACC) and waters of the Weddell Sea. Less distinct dominance has been noted in ACC waters than in waters of the Weddell Sea. In the latter, the dominance pattern was more distinct, and the total variability of larval forms less pronounced. This discrepancy seems to be due to a more advanced seasonal state of the plankton population in ACC than in Weddell-Sea waters. In 'pure' WeddellSea waters a complete disappearance from the larval population of the usually most abundant E. superba larval form (Form 5') has been discovered. Such unusual combination of larval forms in these waters is suggested to be characteristic of a separate subpopulation of E. superba.
\end{abstract}

\section{INTRODUCTION}

One of the most characteristic features in the larval development of euphausiids is the ability to develop in several different but parallel pathways and, consequently, to pass through different forms ('instars') at the same developmental stage. A number of papers deal with various aspects of this phenomenon (e.g. Mauchline and Fisher, 1969; Silas and Mathew, 1977 ; Endo and Komaki, 1979).

The conditions which determine the developmental route are of particular ecological interest. Alternative developmental pathways are reflected in changes in larval forms (or changes in dominance). Euphausiid larvae may be represented in the plankton by various numbers of forms. Some of these forms are captured very regularly, others much more rarely. The first type of larvae is usually named 'dominant forms' (MacDonald, 1927; Einarsson, 1945). Dominance of certain forms reveals that the main larval mass develops predominantly through one of the possible pathways (dominant developmental pathway). In other places and under other conditions, a different larval form of the same euphausiid species may dominate. Such deviations are known as phenomenon of change in dominance'.

Larvae of rare forms develop simultaneously through alternative parallel pathways. Among these are larvae called 'subdominants' (Makarov, 1974a). Morphologically these are most closely related to dominant forms. Next to the dominant forms, they are the most regularly present larval class in the plankton. All remaining larval forms may be much rarer or be totally absent in the plankton. This is, of course, true for species with alternative developmental routes ${ }^{*}$ and, in particular, for Euphausia superba (Fraser, 1936; Mauchline and Fisher, 1969; Makarov, 1974 a).

Patterns of changes in the total number of larval forms of Euphausia superba - accompanied by changes in dominance - have been reported by Makarov (1972a). In short, for the Furcilia-I stage, the change in dominants from Form $5^{\prime}$ towards less developed forms proceeds in accordance with the following 'rules': (1) the variability of different forms increases; (2) the number of individuals of each form increases; (3) such increase concerns primarily subdominant forms. Changes in the opposite direction (towards more advanced forms) lead to reversed ten-

- Alternative larval development is not intrinsic to all euphausid species. In some species the developmental line of definite larval stages is rigidly determined, in others the above-mentioned developmental irregularities are expressed more or less intensively (Einarsson, 1945; Mauchline, 1965; Zelickman, 1968) 
dencies. Form 5 ' is the most usual dominant form in the development of E. superba (Fraser, 1936; Makarov, 1974 a); it may be called a ma in dominant. Changes in dominance are accompanied by deviations in other, parallel developmental pathways. They modify the total variability ranges of larval-form combinations. Consequently, the dominance of this or another larval form may serve as index for the degree of larval variability in the plankton of any region.

Our material of Euphausia superba larvae permits to characterise the pattern of larval-form variability and, in particular, the changes in dominant forms. This phenomenon, which is a function of regional environmental differences represents the subject of this paper. For our purpose we use only larvae of different forms of the Furcilia-I stage (in the sense of Fraser, 1936).

\section{MATERIAL AND METHODS}

Euphausia superba larvae were captured during the expedition of RV 'Akademik Knipovich' (February 27-March 17, 1969) in the Scotia and North Weddell Seas with an opening-closing Juday net $(36 \mathrm{~cm}$ diameter, 38 mesh $\mathrm{cm}^{-1}$ ) from depths of 500 or $100 \mathrm{~m}$. The collected larvae were counted and arranged according to forms using Einarsson's symbol (') based on nonsetose pleopod pairs. Standard hydrological observations were carried out at every station. Counts of geostrophic currents were made from the 1,000 decibar surface. These data turned out to be very useful as indicators of environmental differences in the sample regions of E. superba.

\section{MAJOR FEATURES IN THE DISTRIBUTION OF EUPHAUSIA SUPERBA LARVAE}

During our observations, the larval population studied was in rather early development, but spawning was already completed; larvae from Calyptopis-II (I) to Furcilia-II stages were mostly abundant in the plankton. For detailed information on larval development during the year under consideration consult Makarov (1974 b). Furcilia-I-stage individuals were found everywhere, but in different regions they are characterised by different combinations of forms (Fig. 1). Larvae of all forms, from 1' to 5', were present. (Larvae in the non-pleopod form of Furcilia-I stage are excluded here.) In most cases dominance of Forms $3^{\prime}$ and $4^{\prime}$ prevailed; only at 2 stations did Form $5^{\prime}$ dominate.

Changes in form combinations, connected with dominance changes, usually corresponded to our 'rules' (particularly so, with respect to subdominants). The most regularly found situation, related to the 'rules', pertained to larvae from stations located in the western part of the investigated region (eastwardly up to St. 72), as well as at several points in the middle part of the region (St. 58,76, 77, 104, 106, 109). With respect to dominant forms (Forms $3^{\prime}$ or $4^{\prime}-5^{\prime}$ ) the total number

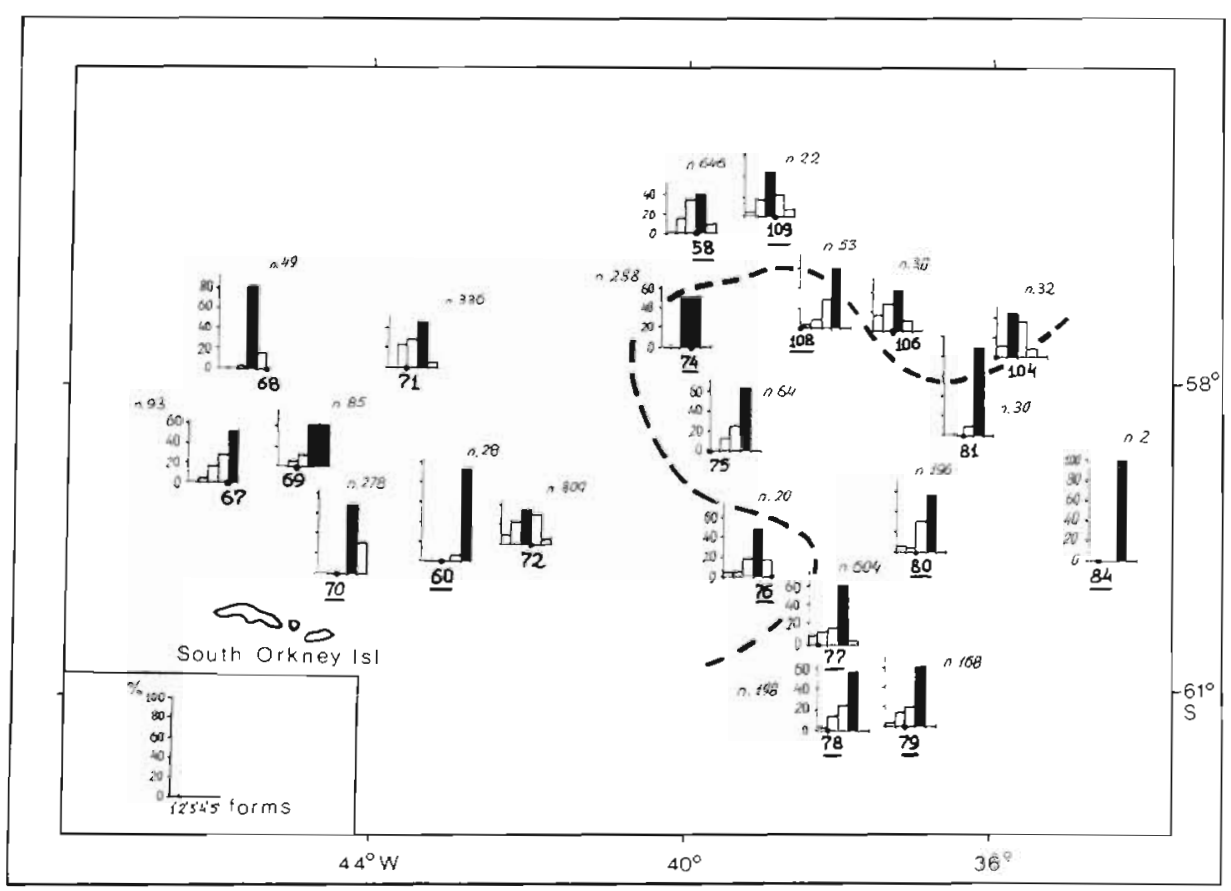

Fig. 1 Euphausia superba. Composition of larval forms of Furcilia-I stage and their dominant forms (black columns) in the Scotia Sea, February-March, 1969. Underlined station numbers indicate sampling down to $500 \mathrm{~m}$ 
of larval forms captured was more numerous in case of Form 3', less numerous in Forms 4' or 5'. Notably, more variable combinations of larval forms tend to be distributed more towards the north. However, the combinations of larval forms were apparently unusual at several stations: in spite of the dominance of Form 4', only subdominants $3^{\prime}$ were found here, but individuals of Form $5^{\prime}$ (which must also be considered as subdominants) were completely absent. Based on the criterion of presence or absence of larvae of Form $5^{\prime}$ we attempted to divide our study region into 2 parts. As seen in Figure 1, the zone of absence of these larvae lies in the eastern and southeastern parts of the region investigated. St. 104 and 106 are outside the last-named zone. Since a small total number of larvae were collected at these stations, it may be assumed that Form $5^{\prime}$ larvae simply avoided the net. However, St. 77 was included in this region, because Form $5^{\prime}$ larvae were distributed only in the 0-25 $\mathrm{m}$ layer, but as usual for this region, larvae were present in the remaining part of the water column.

The above-described patterns of larval distribution reveal an interesting relationship with details of local hydrological conditions.

Two water bodies - the West Wind Drift or Antarctic Circumpolar current $(\mathrm{ACC})$ and waters of the Weddell Sea - interact in the southern part of the Scotia Sea (Deacon, 1933). They form a frontal zone of mixing the so-called 'Secondary Frontal Zone' (SFZ; Solyankin, 1969). Interacting, these water bodies ${ }^{*}$ generate a system of meandres. The localisation of the meandres is determined, in particular, by the relief of the sea bottom. However, their definite position deviates annually as well as seasonally (Maslennikov and Solyankin, 1979).

The system of geostrophical currents was, in the summer of 1969 , characterized by a significant spatial irregularity, expressed in the formation of usually northwardly and southwardly directed meandres (Fig. 2). This has lead to irregularities in the distribution of physical characteristics. The formation of these meandres which penetrate very far into neighbouring water bodies determines the complex configuration and fine structures of SFZ.

The intermediate maximum of warm deep-watermass temperatures $\left(T_{\max }\right)$ is, obviously, the most representative characteristic for identifying the position of SFZ. This characteristic is not influenced by atmospheric processes and, consequently, provides a very clear picture regarding the position of ACC and Weddell-Sea waters.

- The waters of ACC and Weddell Sea should be considered as two separate spatial modifications of different nature, belonging the same Antarctic (surface, in particular) water mass (Maslennikov, 1979)
The distribution of $\mathrm{T}_{\max }$ in the area investigated is shown in Figure 3 . The lowest values of $\mathrm{T}_{\max }$ $\left(0.3^{\circ}-0.4^{\circ} \mathrm{C}\right)$ were observed in the southeastern part of the region, the highest $\left(>2.0^{\circ} \mathrm{C}\right)$ in its northern part. The lowest $T_{\max }$ values probably correspond to 'pure' Weddell waters, but those above $2.0^{\circ} \mathrm{C}$ to ACC waters. The boundary between these waters coincides subsequently with maximum horizontal $\mathrm{T}_{\max }$ gradients. The position of SFZ determined in this way may differ from that determined in accordance with the distribution of physical and chemical surface characteristics. It is due to blocking of the deep-water mass by relatively spacious shallows (for instance, near the islands).

Figure 4 shows the position of SFZ (based on the $T_{\text {max }}$ gradient and the distribution of physical and chemical surface characteristics), as well as the position of various waters which constitute different districts of a pecular hydrological nature. Corresponding parts of SFZ serve as boundary between them. This rather complicated situation is typical of this region (see also Vladimirskaya et al., 1976). The submeridional direction of SFZ near St. 73-78 may be explained by the presence of 2 northwardly and southwardly directed meandres, positioned west and east of $40^{\circ} \mathrm{W}$ (Fig. 4). The northwardly directed meandre consists of 'pure' Weddell waters which practically do not mix with ACC waters. This part of the region we call 'Eastern District'. The southwardly directed meandre consists of mixed waters which include a high percentage of ACC waters ('Central District'). The deep waters of the Weddell Sea which penetrate into the Scotia Sea west to the South Orkney Islands undergo mixing processes with ACC waters, as well as with waters spreading from the Pacific sector (along the South Shetland Islands). These mixed waters are distributed over a great part of the 'Western District'. The blocking role of the large, well-developed shelf of the South Orkney Islands determines the restricted distribution of 'pure' deep water of the Weddell Sea only within the limits of a small part of the 'Western District'. The presence of these waters leads to the formation of a zone with a high horizontal $T_{\max }$ gradient near the South Orkney Islands. Due to the more independent spreading of surface Weddell-Sea waters, the surface position of SFZ is located here more to the north and thus results in spatial differences in regard to the depth position of SFZ (Fig. 4).

The districts considered above were established on the basis of oceanographical data coinciding with the preliminary subdivisions based on larval occurrence (Fig. 1). The data on larval-form combinations were calculated according to the following equation:

$$
\mathrm{A}=\frac{\sum \mathrm{Bn}}{\sum \mathrm{n}}
$$




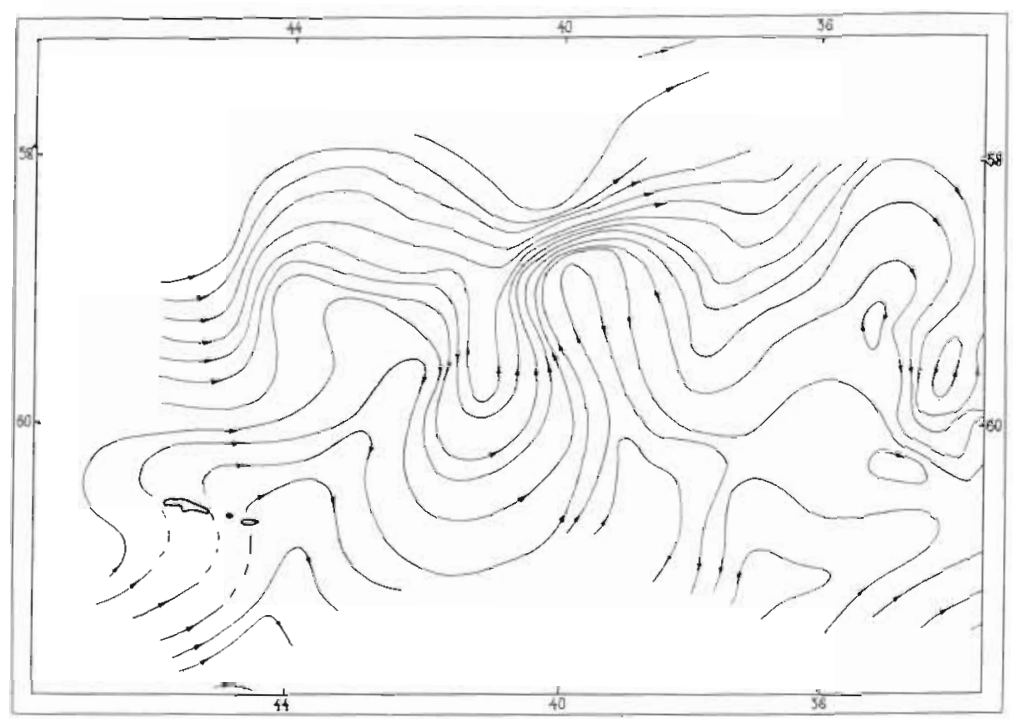

Fig. 2. Surface geostrophic currents in Scotia Sea February-March, 1969

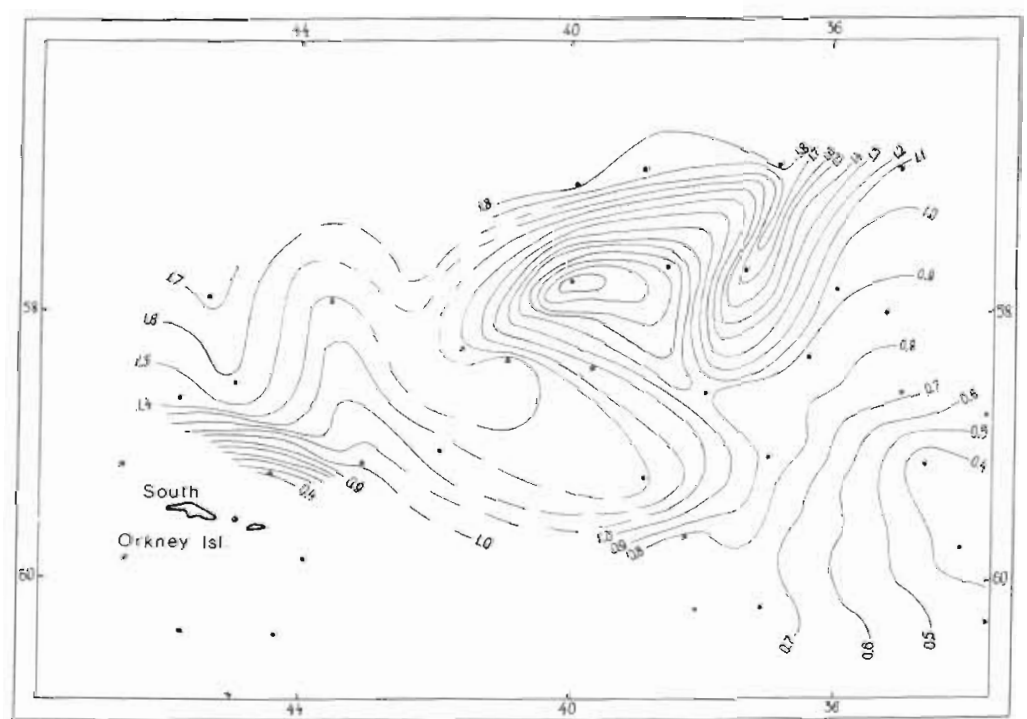

Fig. 3. Distribution of intermediate maximum temperature $\left(T_{\max }\right)$ of the warm-deep-water mass in the Scotia Sea, FebruaryMarch, 1969

where: $\mathrm{B}=\%$ of all larvae forms in Furcilia-I stage; $\mathrm{n}$ $=$ numbers of larval forms $\left(1^{\prime}=1,2^{\prime}=2 \ldots 5^{\prime}=5\right)$. A reflects the quantitative proportion and degree of dominance of larval forms at each station. The lower its value, the larger the variability and the larger the proportion of all forms and vice verse. The same pertains to the degree of dominance of any larval form. The more distinct the dominance, the higher the value of the index A. It is necessary here to stress that the most distinct dominance of Euphausia superba larvae is characteristic of Forms $4^{\prime}$ and $5^{\prime}$, but not of Forms $2^{\prime}$ or 3'. Consequently, the value of $\mathrm{A}$ also indicates, which form dominates in a specific case.

Calculated values of $A$ were plotted (Fig. 5). As can be seen, A invariably increases in places, where Wed- dell waters are present (Eastern and Western Districts; Fig. 4). On the contrary, extensive penetration of ACC waters results in a lower value of $\mathrm{A}$ (St. 72, 76, 77). Consequently, the variability of larval forms and their distinct dominance depends directly on the nature of the larva's habitat waters " The variability of larval forms is much higher, but the degree of dominance less

- In the western part of the region, the larvae did not perform diumal vertical migrations: they permanently concentrated only in the surface $(25 \mathrm{~m})$ layer. Hence, samples from the upper $100 \mathrm{~m}$ must completely reflect the composition of local larval forms. In the eastern part, the larvae migrated. It was here that the most regular deep-sampling was performed. Consequently we may suppose, that the larval population was recorded in our samples adequately. 


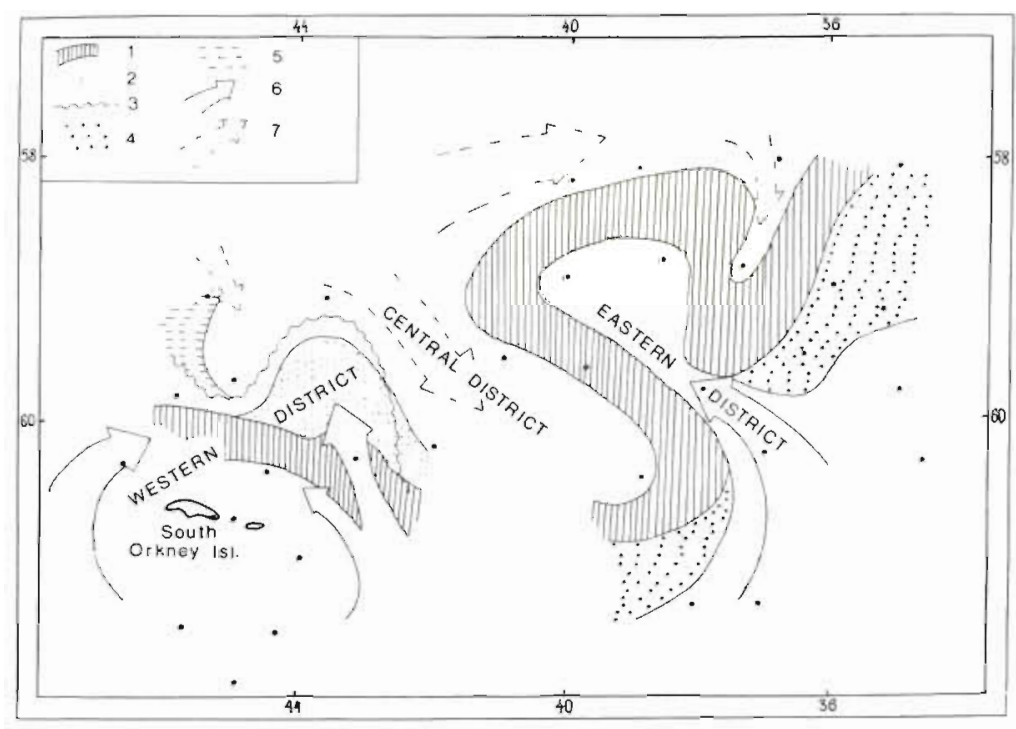

Fig. 4. Position and structure of Secondary Frontal Zone (SFZ), February-March, 1969. 1: zone of maximum $\mathrm{T}_{\max }$ gradients; 2 : area under influence of deep Weddell waters; 3: surface position of SFZ; 4,5: areas under influence of (4) Antarctic Circumpolar current (ACC) and (5) surface Weddell-Sea waters; 6,7: direction of spreading of (6) deep Weddell-Sea waters and (7) ACC waters

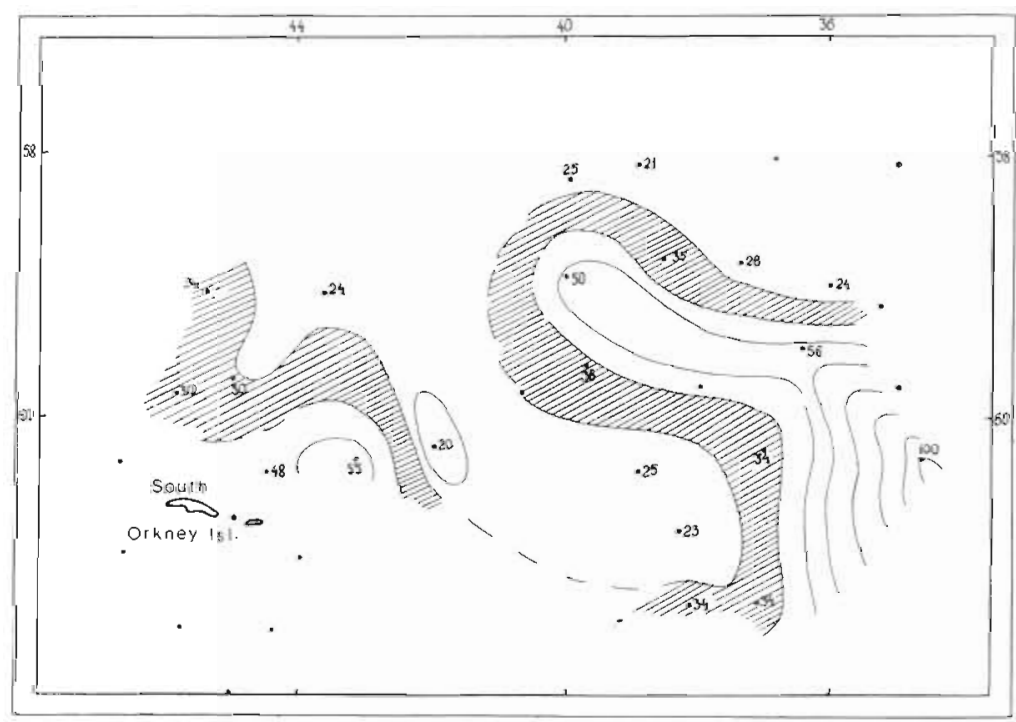

Fig. 5. Euphausia superba. Larval-form combinations of Furcilia-I stage expressed in values of Index A

expressed in ACC, than in Weddell waters. A comparison of Figures 4 and 5 reveals, that the lines of $A$ values coincide rather well with the location SFZ. This coincidence reflects changes in larval-form combinations in the plankton (as we move from one water body into another). We name the belt of $A=30-40$ 'transmission zone'.

As has already been noted, the width of the spreading of Weddell-Sea waters into the 'Western' and 'Eastern Districts' differs. The most distinct boundary between ACC and Weddell-Sea waters in the Eastern part of the region concerned creates also a sharp deviation of the A values. The situation in the Western part of the region is less definite. The 'transmission zone' is much wider here. This fact supports our conclusions regarding the more complex composition of these waters and the more extensive local mixing of the waters in this part of the region.

\section{DISCUSSION}

Studies on copepods (Vladimirskaya, 1978) and on larvae of Euphausia frigida and Thysanoessa macrura (Makarov, 1977, 1979) have shown that the seasonal state of plankton development in Weddell-Sea waters 
is invariably less advanced than in the ACC. During our observations phytoplankton in the ACC was very scarce, often completely absent. In Weddell-Sea waters a moderate bloom might be found rather often (Dr. O. A. Movchan, pers. comm.). Obviously, the feeding conditions of the larvae were better in WeddellSea waters, and if so, the change of dominance, which we have recorded is, undoubtedly, the direct result of seasonal discrepancies between spatial modifications of the water bodies concerned.

Field as well as experimental observations show that the change in dominants depends on environmental conditions, in particular on the food resources available in the plankton (Einarsson, 1945; Mauchline, 1965; Le Roux, 1973, 1974). The better the feeding conditions, the more buds of future pleopods form inside the abdominal somites at the Calyptopis-III stage, and the more advanced forms of Furcilia-I stage develop from that calyptopis stage.

Seasonal differences in dominance are well known, for example, for Thysanoessa spp. and for Meganyctiphanes norvegica (Einarsson, 1945; Mauchline, 1965; Zelickman, 1968). Seasonal patterns of change in dominance (and also of changes in the variability of larval forms) are also very characteristic for Euphausia superba (Makarov, 1974a; his Table 1). In a comparatively early phase of the breeding season $(1965,1967)$ Forms $4^{\prime}$ and $5^{\prime}$ were much more numerous than other forms. At the end of the breeding season $(1969,1970)$ such notable distinction of these forms was not obvious for the larval population of E. superba. Consequently, $E$. superba larvae develop through the main dominant pathway at the beginning of the breeding season. Thereafter, the decrease in the quantity of available phytoplankters probably results in an increase of the degree of variability of larval forms, i.e. in an increase in the ecological importance of other, non-dominant developmental pathways and, in a change of the dominant form.

The above-mentioned situation does not exhaust the diversity in the patterns of larval-development variability in Euphausia superba. Indeed, as we have seen, Form 5' was completely absent in the Eastem District (Figs 1 and 4). This fact cannot be explained on the basis of our 'rules' of dominance change (when Form 4' is dominant, Form 5' must be present without fail). The disappearance of some forms from the larval population represents a temporary feature in euphausiid ontogenesis. But the absence of Form 5' (main dominant form in the ontogenesis of $E$. superba) under the above-mentioned circumstances should have a more fundamental cause. As is well known, the sequence and composition of larval forms which constitute a developmental cycle in Euphausiacea is of taxonomic significance (Lebour, 1926; Einarsson, 1945). This con- cept speaks for the suggestion that, in the abovementioned case, we are dealing at least with a subunit of the E. superba population.

Several attempts were made to separate the population of Euphausia superba into several subunits (e.g. Marr, 1962; Makarov, 1972; Mackintosh, 1973; Everson, 1976; Latogursky, 1979). One of the criteria employed for subunit (subpopulation) identification in this species is the connection in the distribution of individuals with different water bodies (this is also true for other zooplankton species; Beklemishev, 1969). Individuals inhabiting various latitudinal belts may. for example, show differences in regard to growth rate and age composition (Marr, 1962; Mackintosh, 1972, 1973). It is essential to note that larvae of E. superba with anomalous composition of forms of the Furcilia-I stage were distributed in 'pure' Weddell-Sea waters ('Eastern District'). Hence, the disappearance of Form $5^{\prime}$ from the population of larvae inhabiting 'pure' Weddell-Sea waters might indicate a special nature of these larvae. They could well belong to some separate ('Weddell') population of E. superba, which did not pass through Form 5'. For Antarctic euphausiid species, the presence of 2 physiological races, which breed on either side of SFZ has been postulated earlier (Makarov, 1977, 1979).

The mixing of waters, as well as the more complex composition of planktonic larval forms observed in other districts, create serious problems of analogous definition. This will be the subject of future investigations. Another yet unsolved problem of particular interest concerns the reasons for the disappearance of Form $5^{\prime}$ from the developmental cycle of the suggested subpopulation.

\section{LITERATURE CITED}

Beklemishev, K. V. (1969). Ecology and biogeography of the open ocean (Russ.), 'Nauka', Moscow

Deacon, G. E. R. (1933). A general account of the hydrology of the South Atlantic ocean. 'Discovery' Rep. 7: 171-238

Einarsson, H (1945). Euphausiacea. I. Northern Atlantic species. 'Dana' Rep. 27: 1-185

Endo, Y., Komaki. Y (1979). Larval stages of Euphausiids with descriptions of those of Thysanoessa longipes Brandt. Bull. Jap. Sea. Reg. Fish Res. Lab. 30: 97-110

Everson, I. (1976). Antarctic krill: A reappraisal of its distribution. Polar Rec. 18: 15-23

Fraser, F. C. (1936). On the development and distribution of the young stages of krill (Euphausia superba). 'Discovery' Rep. 14: 1-192

Latogursky, V I. (1979). Determination of non-dependent populations of Antarctic krill (Russ.). Rȳbnoe khosaistvo 10:12-14

Lebour, M. V. (1926). A general survey of larval Euphausiids with a scheme for their identification. J. mar biol. Ass. U. K. 14: 519-527 
Le Roux, A. (1973). Observation sur le développement larvaire de Nyctiphanes couchii (Crust acea: Euphausiacea) au Laboratoire. Mar. Biol. 22: 159-166

Le Roux, A. (1974). Observation sur le développement larvaire de Meganyctiphanes norvegica (Crustacea: Euphausiacea) au laboratoire. Mar. Biol. 26: 45-56

MacDonald, R. (1927). Irregular development in the larval history of Meganyctiphanes norvegica. J. mar biol. Ass. U. K. $14: 785-794$

Mackintosh, N. A (1972). Life cycle of Antarctic krill in relation to ice and water conditions. 'Discovery' Rep. 36 $1-94$

Mackintosh, N. A. (1973). Distribution of post-larval krill in the Antarctic. 'Discovery' Rep. 36: 95-156

Makarov, R. R. (1974a). Dominance of larval forms in Euphausiid (Crustacea: Eucarida) ontogenesis. Mar. Biol. 27: $93-100$

Makarov, R. R. (1974b). Larvae of Euphausia superba Dana in plankton from the Sea of Scotia. (Russ.) Trudȳ vses. nauchnoissled. Inst. morsk. ry b. Khos. Oceanogr. 99: 84-103

Makarov, R. R. (1977). Larval distribution and some aspects of reproduction ecology of Euphausia frigida Hansen, 1911 (Crustacea: Euphausiacea) in the Southern part of Scotia Sea (Russ.). Oceanologia 17: 324-332

Makarov, R. R. (1979). Larval distribution and reproductive ecology of Thysanoessa macrura (Crustacea: Euphausiacea) in the Scotia Sea. Mar. Biol. 52: 377-386

Marr, J. W. S. (1962). The natural history and geography of Antarctic krill (Euphausia superba Dana). 'Discovery' Rep. 32: $33-464$
Maslennikov, V. V. (1979). Regional pecularities of the Antarctic surface waters in the south-west part of Atlantic sector (Russ.). In: 'Antarctic'. Rep. Soviet Comm. Ant. Res., Vol. 18, 'Nauka', Moscow, pp. 134-139

Maslennikov, V. V., Solyankin, E. V. (1979). On annual shift of the water interaction zone in Weddell Sea and Antarctic Circumpolar current (Russ.). In: 'Antarctic', Rep. Soviet Comm. Ant. Res., Vol. 18, 'Nauka', Moscow, pp. 118-122

Mauchline, J. (1965). The development of the euphausiid, Thysanoessa rashii (M. Sars). Crustaceana 9: 31-40

Mauchline, J., Fisher, L. R. (1969). The biology of euphausiids. In: Russell, F. S., Yoe, C. M. (eds) Advances in marine biology, Vol. 7. Academic Press, London, New York, pp. 1-454

Silas, E. G., Mathew, K. J. (1977). A critique to the study of larval development in Euphausiacea. In: Proceedings of symposium on warm water zooplankton (spec. publ.), Mar. Inst. Ocean., Dona Paula, Goa, India, pp. 571-582

Solyankin, E. V. (1969). Changeability of the frontal zone position of the Scotia Sea. (Russ.) Mezhdunar. Rybolov. 11: $42-48$

Vladimirskaya, E. V. (1978). Age composition of the populations of mass copepod species in the Southern part of the Scotia Sea (Russ.). Oceanologija 18: 307-311

Vladimirskaya, E. V., Makarov, R. R., Maslennikov, V. V., Movchan, O. A. (1976). Some traits of phytoplankton distribution in the Southern part of the Scotia Sea in spring (Russ.). Oceanologija 16: 1069-1075

Zelickman, E. A. (1968). Some features of evolution of the family Euphausiidae (Crustacea, Euphausiacea) in neritic and oceanic areas (Russ.). Zool. Zh. 47: 1314-1327 